\title{
Experiences with the use of Snap Circuits and Arduino boards as tools for human development with students in an insular Colombian community
}

\author{
J. L. Villa, $\mathrm{PhD}^{1}$, O. Bruno, $\mathrm{PhD}^{1}$, and T. Jiménez, $\mathrm{PhD}^{1}$ \\ ${ }^{1}$ Universidad Tecnológica de Bolívar, Colombia,jvilla@utb.edu.co, oriana.bruno@gmail.com, tjimenez@utb.edu.co
}

\begin{abstract}
Insular communities in Colombia have had significant lags in human development. As a strategy to help overcome these shortcomings, this paper proposes the use of technological tools such as Snap Circuits and Arduino boards. The results obtained in the first phase of the research show that this type of technology succeeds in attracting secondary school students and contributes to the generation of capacities. It should also be noted that, in order to positively impact the human development indices of these populations, a long-term effort is required that also addresses different dimensions and strategies..
\end{abstract}

Key Words: Snap Circuits, Arduino, human development, engineering for society

\section{INTRODUCTION}

In recent years, a major effort has been made to introduce the concepts and tools of science and technology into the curriculums of primary and secondary education [1]. Complementary to this, some efforts have been made to utilize technological tools that promote learning through games [2], while others have strived to link centers of technology and engineering with teachers in educational institutions with the goal of generating capacities in talented students who might take up careers in science or technology [3].

However, the social context in which the learning process is carried out has a direct impact on the results obtained from children and young people. Thus it is necessary to reflect on strategies that can contribute to the strengthening of values, the generation of capacities, and the improvement of student expectations. Some communities in which many basic needs go unmet are very pessimistic about their future. In a related way, it has been noted that high school students are losing interest in accessing higher education after completing basic secondary education. Although these observations correspond only to the community in which this research was carried out, some teachers and consultants have confirmed that it is a pattern which is repeated in many vulnerable communities.

As such, this document proposes a strategy that includes technology, art, skills training, and vocational guidance as tools to address the human development of students from vulnerable communities. The proposed strategy has been implemented in an island community in the Colombian Caribbean and the results show that students with diverse interests are motivated to participate in training activities using technologies such as Snap Circuits and Arduino boards.
On the other hand, the results also show that long-term support is required to provide evidence of changes in the participating students' perception of the future.

The article is structured as follows. In Section II we describe the community of Caño del Oro, emphasizing the preliminary perceptions of its inhabitants regarding the vulnerabilities and opportunities of the island and the educational institution. Section III presents the strategy designed to contribute to the human development of the community. Section IV gives the main results obtained in the use of technological tools such as Snap Circuits and Arduinos. Finally, Section $\mathrm{V}$ provides a brief discussion and the main conclusions of the work.

\section{THE COMMUNITY OF CAÑO DEL ORO}

This section presents a description of the Caño del Oro community and of the San José Educational Institution of Caño del Oro. It also summarizes the results of an analysis of the perception the vulnerability and opportunity held by the student community. A more extensive description can be found in [4] and [5].

\section{A. Description of the Community}

Caño del Oro - along with Bocachica, Punta Arena and Tierrabomba - is a corregimiento of the city of Cartagena de Indias, a touristic and cultural district of Colombia. Caño del Oro is located on the southeast side of the island of Tierra Bomba, approximately 1.2 kilometers, a 20 minute boat ride, from the city. The community is made up of 414 houses in an area that consists of approximately 7 hectares. According to data from the National Administrative Department of Statistics (DANE), the community of Caño del Oro - consisting of 1708 individuals, $52 \%$ women and $48 \%$ men - has an Afrodescendant majority (98.7\%). The average age of the population is relatively young $(40.5 \%$ are between 5 and 24 years of age), and this figure is reflected in the number of students in the educational institute, where 510 students attend classes (approximately $25 \%$ of the total population). In regards to the juvenile population, it should be noted that the rates of teenage pregnancy are high, with the pregnancy of girls aged

Digital Object Identifier (DOI): http://dx.doi.org/10.18687/LACCEI2018.1.1.46 ISBN: 978-0-9993443-1-6 ISSN: $2414-6390$

16" LACCEI International Multi-Conference for Engineering, Education, and Technology: "Innovation in Education and Inclusion", 19-21 July 2018, Lima, Peru. 
between 15 and 19 representing $44.4 \%$ of the total number of pregnancies. Additionally, $19.4 \%$ of households are headed by the mother [6].

Historically, the people of Caño del Oro have dedicated themselves to activities related to the sea: fishing and piloting commercial and recreational boats. According to the results of the participatory assessment conducted in 2011 [6], people working in agriculture and fisheries represent $44 \%$ of the local labor force, with those main productive activities being followed by trade, construction and transport (which represent $21.4 \%, 14.5 \%$ and $6.8 \%$ respectively).

It is extremely important to note that the Caño del Oro community lacks basic services, which increases the risks to the well-being of the population that result from the lack of sanitation and the consumption of non-potable water. In the absence of these services, we have found that the inhabitants have developed adaptive measures to mitigate the impacts of these deficiencies.

It should also be noted that the estimated absolute illiteracy rate is $5.9 \%$ and the functional rate is $7.7 \%$.

\section{B. Description of the Educational Institution San Jose de Caño del Oro}

The Educational Institution named San José de Caño del Oro is located in the coastal zone of the rural corregimiento of Caño del Oro, on the island of Tierrabomba. It is an academic institution with a scheduling framework that is known as calendar A, which has three school sessions: morning, afternoon and night. It includes courses for preschool, elementary, high school levels, and also offers a technical degree with courses in the Operation of Tourist Services and the Operation of Integral Logistic Processes, which are taught in the afternoon. The school has 510 students enrolled in classes taught by 25 teachers, of which 20 are provisional and few have a specialized degree (data provided by the rectory of the educational institution in December 2015).

The Educational Institution has 13 classrooms. Although progress has been made in the improvement of the classrooms and the national government has provided them with computer equipment, the school suffers from various problems that directly affect the quality of life of students and the learning environment.

\section{Perception of Vulnerabilities and Opportunities for the Caño del Oro Student Community}

Before designing an educational strategy for the students, the research team conducted a preliminary investigation into the perception of vulnerabilities and opportunities held by the community itself. With this goal in mind, a participatory methodology was used that employed qualitative research techniques, such as participant observation, in-depth interviews and focus groups.

By analyzing field journals, interviews and focus groups with students (4th, 5th, and 6th grade), mothers, teachers, and community members, it was possible to characterize the perceptions held by community members in terms of their vulnerabilities and opportunities. Among the vulnerabilities emerged the need to strengthen the educational offerings through the education of values, the strengthening of reading and writing skills, and a vocational orientation with respect to what students can be and do once they have finished with their educational formation.

It should be noted that during focus groups, the students in the 9th and 10th grade show euphoria regarding the possibility of accessing the universities located in the urban area, while the students in their last year, arriving at the point of making decisions regarding their educational future, proof to be more disheartened, more disenchanted and with limited imagination regarding a future that seems to inevitably end with the possibility of being a boat captain or wife of a good husband, a hardworking and respectful man.

In terms of strengths, all community members recognize their shared cultural heritage, with special emphasis on folkloric dance, as the maximum expression of their identity, which is linked to their condition as an insular, Afrodescendant community.

Due to its insularity as an island community, Caño del Oro is characterized by a feeling of isolation from the city, which translates into feelings of institutional abandonment, passivity, and the perception of being subordinate subjects who therefore have the right to benefit from constant aid.

With these premises, we set out to design an intervention strategy that integrates training in science, arts and skills in order to contribute to the human development of students of the Educational Institution San José de Caño del Oro.

From the technological point of view, art and technology can hardly be considered novel. However, only for the last decade has it been possible to have inexpensive and easy-touse tools that allow a wider audience to access technology, including children, seniors, and people with varying skill levels. Thanks to the emergence of tools such as Arduino (www.arduino.cc) and Raspberry Pi (www.raspberrypi.org) it has been possible to significantly expand the access to technology that is enjoyed by people who are experts in neither the arts nor technology.

\section{INTERVENTION STRATEGY}


The proposed intervention strategy is based on the three pillars outlined in the guide proposed by the Center for the Integration of Research, Teaching, and Learning - CIRTL [7]. The pillars established in this guide are: teaching as research, learning community and learning through diversity.

Taking into account the three outlined principles, the following subsections detail the application of each of these principles in the intervention strategy.

Teaching as Research

This principle tends to use the practice of teaching as a research approach. The guide proposed in [7] outlines seven conceptual steps to follow.

1. Foundational knowledge of learning

2. Create goals for student teaching

3. Develop a hypothesis for practices to achieve learning objectives

4. Define measures of success

5. Develop and implement teaching practices with an experimental design

6. Collect and analyze data

7. Reflect, evaluate and iterate

The main objective of these practices is to motivate students' interest in engineering or technological careers through practices related to electrical circuits and programming algorithms.

Our hypothesis in terms of teaching is that students can learn basic concepts of electronics and later use these concepts to learn programming. Furthermore, our hypothesis from the point of view of human development is that, to the extent that students learn from this type of technology, they can consider new possibilities for their training after high school and become better prepared to access higher education in the areas of engineering or technology.

To measure the success of the first stage, i.e. the teaching of electronics, a number of students volunteered to participate in an activity in which they would give a presentation to their fellow classmates. For this activity, after the initial teaching process, the students prepared an experiment which they explained to their classmates on a day dedicated to the activity. For the second stage, i.e. the teaching of algorithm programming, success was measured with the number of students who participated in the final application project. This final project was also presented to all of the students in the educational institution on a day dedicated to this activity.

The practices that were implemented are based on teaching material that accompanies the technological tools that were chosen for the activities.

Three instruments were designed for data collection. The first instrument consists of an in-depth interview at the beginning of the intervention. The second instrument consists of a survey after the teaching of electronics. The third instrument consists of a survey of each participant with the objective of evaluating the evolution of students' interests after the teaching of programming.

The objective of designing two learning moments seeks to comply with the seventh conceptual step, in which teaching guides and evaluation instruments are adjusted based on the information obtained in the first survey.

Learning Community

To establish the learning community, the following actors are identified:

1. The directives and teachers of the educational institution where the activity takes place

2. Students directly involved in teaching activities

3. Students not directly involved in teaching activities

4. Engineering students guided by a team of university professors.

To develop the learning community, the following steps are proposed:

1. Obtain the support of the directors of the educational institution and with this support link to at least one teacher of the educational institution.

2. Make teachers aware of the opportunities provided by the learning activity.

3. Motivate a group of students to become part of the training group.

4. Carry out complementary activities that include students not directly linked to the training

5. Carry out training activities with the teachers in the educational institution in order to generate interest in receiving technological training in the longer term.

Learning through Diversity

Taking into account that the island communities in the Colombian Caribbean are partially isolated, the socioeconomic conditions of the students in the educational institution can be considered uniform in general terms. Due to this, the following diversity criteria were established:

1. Ensure the participation of 7 th to 10 th grade students

2. Advocate for gender equality in groups

3 . Ensure participation of students with varying degrees of academic achievement.

\section{RESULTS}

This section presents the results of the implementation of the strategy (described in section III) in the educational community of Caño del Oro (described in section II). First, we explain the technological tools used, then to the implementation of the design, and finally the results obtained by the instruments for following and measuring success rates.

16" LACCEI International Multi-Conference for Engineering, Education, and Technology: "Innovation in Education and Inclusion", 19-21 July 2018, Lima, Peru. 
As is usual in this type of research, we use a mixed research methodology: a small population group and valuations made with questionnaires, qualitative interviews and observation [10], [11].

\section{Technological tools}

There are several technological tools for teaching circuits. Some are specifically oriented towards electric circuits and others are combined with robotics or mechatronics. Based on the assessment made in [8], we evaluated Roominate, LittleBits, Snap Circuits Jr, Robotic Arm Edge and Lego Mindstorms EV3.

The criteria that were evaluated are:

- Suitability for a wide range of ages

- Support material

- Cost

- Availability in the country

Both Robitic Arm Edge and Lego Mindstorms have extensive documentation and are available in Colombia, but their cost is high, and although their parent companies exhibit projects with children, it is clear that they are more suitable for older students in their later years at educational institutions. Roominate and LitteBits are interesting in that they work under the same concept as Lego, but both have small parts that may not be appropriate for children. Additionally, there does not seem to be support in Spanish and they are more oriented towards motor skills used in construction. Snap Circuits Jr presents 101 experiments with standardized parts for electrical circuits. The material is in Spanish and English and is aimed at students learning about electrical circuits by allowing them to play at building different types of projects.

Taking the above into account, Snap Circuits Jr was chosen as the working kits for the students' initiation into science and technology.

The intention of the second stage is to move to programming and computer use. For this we evaluated the two platforms most used at the time, which are Arduino and Raspberry Pi. Based on the evaluation presented in [9], we note that both platforms were conceived as teaching tools. Both platforms are comparable in cost and size. Arduino comes with an Integrated Development Environment (IDE) programming that can be installed on any commercial operating system. This IDE works on a simplified version of $\mathrm{C}$ language. Raspberry Pi runs a version of Linux which can be programmed in different programming languages. Arduino includes hardware features that allow it to interact directly with analog sensors and motors, while Raspberry Pi assimilates an architecture analogous to a conventional computer.
Taking into account the above, the Arduino platform was selected for this project.

Once the work platforms were chosen, the teaching material was selected. Both Snap Circuits Jr and Arduino provide teaching material that is of good quality and already proven appropriate for teaching children of different ages.

\section{Design implementation}

The deployment of the strategy was guided by the following protocol:

1. Meeting with the rector of the educational institution, presentation of the project and endorsement of the project.

2. Holding focus groups and in-depth interviews with students and the student community in general.

3. Adjusting the contents of the teaching sessions and the design of the sessions. In total, 4 sessions were designed for the teaching of electronics concepts and 4 sessions for the teaching of programming concepts.

3. Requesting the rector's approval for the beginning of the sessions. Additionally, he was asked to appoint a teacher and select a group of 30 students between grades 7 and 10. It was requested that there be no distinction in the academic performance of the students.

4. Execution of the sessions with the students. At the same time, a kit was left available for students who wanted to use it without necessarily being part of the group of students in training. In total, 7 seventh grade students, 6 eighth grade students, 11 ninth grade students, and 7 tenth grade students participated. Another 15 students used the kits without participating in the training sessions.

5. In the third session, students were asked to choose a project to present to their classmates. The selected projects were presented to the other students at the educational institute's science fair. In total, four projects were presented by 14 students to about 75 students at the educational institution.

6. Realization of the survey and measurement of success indicators, which are detailed in the following subsection.

7. Development of the Arduino sessions

8. Final Evaluation

Results of the instruments for following and measuring the indicators of success

The first indicator of success is the number of students who chose to participate in the Science Fair by explaining a project to their classmate. The results are that 14 students participated by presenting four projects, as mentioned in the previous subsection. 8 students did not participate in the activity because they already had other projects to present at the fair. 6 students felt that they were not motivated to present to their peers. 
The instrument of measurement consisted of a survey with 23 questions. The first 8 questions were related to family composition, and the remaining 15 questions assessed their perception of the activity.

32 students answered the survey. Of these 32 students, 29 expressed that they would like to continue university. 7 of these said they would like to pursue technology-related careers.

As for whether they liked the training activities, 22 students marked the category of "A lot" and 9 the category of "Enough". 25 students responded that they understood the explanations, marking the categories of "Enough" and "A lot". 24 students responded concretely and correctly to the question of what concepts they had learned.

Regarding the space used, 18 students responded that they felt "Very Comfortable" and 11 students responded that they felt "Quite Comfortable"

\section{DISCUSSION}

The success indicator of the number of students who participated voluntarily in explaining the activity to their classmates at the educational institution shows that about $70 \%$ of the group was attracted to actively participating in the activities, but also that $20 \%$ of participating students had no greater interest in participating in the activities, and their motivation to participate in the training group had more to do with their interest in doing activities that were different from their normal curricular activities. This is reflected in the group of students who were unable to respond concretely to the question about what concepts they learned in class.

On the other hand, the students who felt motivated to participate in the activity and present to their classmates were the ones who showed comprehension of the concepts that they said they had learned during the sessions.

It is of note that the group of students who responded that they had no interest in continuing to study after high school are concentrated in 9th and 10th grade participants.

The results of this first stage of the project allow us to recognize the relationship between science, technology and human development and the value it has for the formation of a more responsible citizenry. No significant results have yet been obtained regarding the students' improvement in the classroom and their abilities and attitudes towards daily life that allow for the construction of better social relations. Although the students who participated in the science fair received an additional grade in the science course, it is likewise impossible for us to show that students have shown an improvement in their grades overall.

We hope that in the execution of the second stage of the project we can measure with greater certainty the evolution of the students' thinking regarding their life project, although we know that this evolution only occurs to the extent that the intervention is maintained for the long term.

\section{CONCLUSIONS AND FUTURE WORK}

This project proposes an intervention strategy in educational institutions based on the use of technological tools oriented towards education as a means for human development. The proposed intervention strategy makes use of Snap Circuits and Arduinos. This strategy was tested in an educational institution located in an island community in the Colombian Caribbean. The results show that students are motivated to work with these tools, but it is clear that the impact on the human development of students will only be seen in the long term and through further monitoring and evaluation, as well as the support of different strategies that complement this training with additional routes towards the generation of capacities and the encouragement to improve other competences.

In the next stage, the design of the intervention strategy will be complemented with elements of formation in the arts and vocational guidance. Additionally, a basic training session will be carried out in the social aspects associated with the implementation of technologies for the generation of capacities for human and sustainable development that allow for the more complete achievement of the objective of having a positive long-term impact in the community of Caño del Oro. Finally, in this next phase, it would be interesting to have a more detailed follow-up of the students who decided to participate voluntarily in the activities of the project, realized by the teachers of the educational institution.

\section{ACKNOWLEDGMENT}

The authors express their gratitude to the community connected to the Educational Institution San José de Caño del Oro and the community leaders who have endorsed and supported the tests of the intervention strategy. Likewise, they thank the Electronic Devices Society (EDS) of the IEEE for their support with some of the technological kits used in this project.

\section{REFERENCES}

[1] M. G. Domingo and A. B. Garganté. Exploring the use of educational technology in primary education: Teachers' perception of mobile technology learning impacts and applications' use in the classroom. Computers in Human Behavior. Vol 56. pp. 21-28. 2016

[2] Rabia M. Yilmaz, "Educational magic toys developed with augmented reality technology for early childhood education ," Computers in Human Behavior, no. 54, pp. 240-248, 2016.

[3] Kurt Becker and Rod Custer, "Work in Progress: Supporting K-12 Teacher Professional Development through the National Center for Engineering and Technology Education," in 36th ASEE/IEEE Frontiers in Education Conference, San Diego, 2006, pp. 15-16.

[4] T. Jiménez and O. Bruno. Percepción de vulnerabilidades y oportunidades ambientales y sociales del territorio insular. El caso de la Comunidad Estudiantil de Caño del Oro. In: Memorias de la Conferencia Internacional de la Asociación Colombiana de Estudios del Caribe ACOLEC- ¿El Caribe más allá del litoral". El mundo rural? 2015

[5] T. Jiménez and O. Bruno. El reto de la educación en un territorio insular vulnerable: el caso de la comunidad estudiantil de Caño del Oro. In: Memorias del XII Seminario Internacional de Estudios del Caribe: crisis, diálogos y desafíos en el gran Caribe. 2015

16" LACCEI International Multi-Conference for Engineering, Education, and Technology: "Innovation in Education and Inclusion", 19-21 July 2018, Lima, Peru. 
[6] M. Rodríguez, R. Acosta Mesa, \& R. Arrieta Florez, Caño del Oro. Desarrollo productivo e integración territorial: retos del bienestar local. En A. Espinosa, \& J. Alvis, Pobreza rural y desarrollo humano en Cartagena de Indias, 2013.

[7] CIRTL, The Effective Teaching with Technology Course: a guidebook. Madison, Wisconsin, USA: Delta, 2006.

[8] O. Lauren. 6 Toys to Help Your Kid Geek Out. ReadWrite. 2013 (Retrieved from http://readwrite.com/2013/12/10/science-technologytoys).

[9] O. Lauren. Arduino Vs. Raspberry Pi: Which Is The Right DIY Platform For You? ReadWrite. 2013 (Retrieved from http://readwrite.com/2014/05/07/arduino-vs-raspberry-pi-projects-diyplatform)

[10] A. Gunhaart and N. Srisawasdi. Effect of Integrated Compute-based Laboratory Environment On Students' Physics Conceptual Learning of Sound Wave Properties. In Procedia - Social and Behavioral Sciences. Vol 46 pp. $5750-5755,2012$

[11] U. Ostlund, L. Kidd, Y. Wengstrom and N. Rowa-Dewar. Combining qualitative and quantitative research within mixed method research designs: A methodological review. International Journal of Nursing Studies. Vol. 48, Issue 3, p.p. 369-383, March 2011. 